\title{
Multi-jet electrospinning of polystyrene/ polyamide 6 blend: thermal and mechanical properties
}

\author{
Jae Won Yoon ${ }^{1}$, Yaewon Park², Jooyoun Kim³ and Chung Hee Park ${ }^{1^{*}}$ (D)
}

\author{
${ }^{*}$ Correspondence: \\ junghee@snu.ac.kr \\ ${ }^{1}$ Department of Textiles, \\ Merchandising and Fashion \\ Design, Seoul National \\ University, Seoul, Republic \\ of Korea \\ Full list of author information \\ is available at the end of the \\ article
}

\begin{abstract}
Polystyrene (PS) has high thermal resistance thus can be applied as thermally comfortable textile. However, the application is limited due its low mechanical strength. In this study, polyamide 6 (PA6) was blended with PS to improve the mechanical strength of PS, by means of a multi-jet electrospinning. Content ratio of the blend web was measured by chemical immersion test and confocal microscopy analysis. Fiber content was in accordance with the number of syringes used for PS and PA6 respectively. The effects of content ratio on the web morphology, thermal resistance, tensile behavior, air and water vapor permeability, and surface hydrophilicity were investigated. The influence of environmental humidity during electrospinning process on three dimensional (3D) web structure was also reported. PS web produced from higher humidity had more pores and corrugations at the surface. The increased surface roughness and porosity led to the increased hydrophobicity and thermal resistance. Though the blending of PA6 with PS enhanced the mechanical strength, the added PA6 decreased air/water vapor permeability and thermal resistance. The lowered thermal resistance by the addition of PA6 was mainly attributed to higher thermal conductivity of PA6 material and lowered air content with PA6 fibers.
\end{abstract}

Keywords: Multi-jet electrospinning, Polystyrene, Polyamide 6, Thermal resistance, Porosity

\section{Introduction}

Electrospinning process is broadly used to obtain membrane-like webs with submicron to micron fibers (Li and Xia 2004). Electrospun nanofibers, with its large surface area and multiple pores, can be used to construct unique functional nanostructures for composites, filtration membranes, biomaterials, and breathable textile fabrics (Greiner and Wendorff 2007; Li and Xia 2004; Pham et al. 2006). Generally, an electrospinning setup consists of a high voltage source, container (usually syringe) for polymer solution, syringe pump, capillary nozzle, and grounded collector (Pham et al. 2006). When high electric voltage is applied, the surface tension of polymer solution is overcome by the applied electric field. Charged polymer solution forms into jet, forming a Taylor cone, then gets further stretched. Meanwhile, solvent from the polymer jet continuously evaporates and solidifies to form fiber webs on a collector (Reneker and Chun 1996).

(C) The Author(s) 2017. This article is distributed under the terms of the Creative Commons Attribution 4.0 International License (http://creativecommons.org/licenses/by/4.0/), which permits unrestricted use, distribution, and reproduction in any medium, provided you give appropriate credit to the original author(s) and the source, provide a link to the Creative Commons license, and indicate if changes were made. 
Despite the usefulness and availability of electrospinning technique for various product development, its commercial application has been limited mainly due to its poor production efficiency (Teo and Ramakrishna 2006). As ways to increase the polymer throughput and improve productivity, a multi-needle (multi-jet) (Teo and Ramakrishna 2006) setup or roller spinning electrode device (Cengiz et al. 2010; Yener and Jirsak 2012) has been tested. Due to the advantage of multi-jet electrospinning as a simple setup for blending different fibers with desired ratio (Teo and Ramakrishna 2006), several research groups have applied multi-jet device to fabricate nanofibrous textiles. Park et al. (2013) investigated the efficacy of blending polyurethane/polyamide 6 using an angled dual-nozzle electrospinning set up. Ding et al. (2004) studied the mechanical properties of blended web with poly(vinyl alcohol) and cellulose acetate in different ratio. However, there are few studies that thoroughly examined the influence of blend ratio on the web structure and properties as clothing materials.

Polystyrene (PS) and polyamide 6 (PA6) are widely used for in textile industry (Carrizales et al. 2008; Casper et al. 2004; Marsano et al. 2010; Pai et al. 2009). PS has a potential application as breathable textile with thermal comfort thanks to its high thermal resistance, but its application is limited due to its low mechanical property. If a material such as PA6 with good mechanical property can be blended with PS, the blend web can have practical applications as thermally comfortable clothing with the enhanced mechanical property.

In this study, a multi-jet electrospinning set-up (Fig. 1) was used to produce blend webs with PS and PA6, and the effect of content ratio was investigated on the web morphology, thermal and mechanical properties, air and water vapor permeability, and surface hydrophilicity. The influence of environmental humidity during electrospinning process on the three dimensional (3D) web structure was also briefly reported.

\section{Methods}

\section{Materials}

Polystyrene (PS, $\left.\mathrm{M}_{\mathrm{w}}=350,000 \mathrm{~g} / \mathrm{mol}\right)$ and polyamide $6\left(\mathrm{PA} 6, \mathrm{M}_{\mathrm{w}}=10,000 \mathrm{~g} / \mathrm{mol}\right)$ were purchased from Sigma-Aldrich (USA). N,N-dimethylformamide (DMF, 99.8\%), tetrahydrofuran (THF, 99.5\%), formic acid ( $\geq 99.0 \%)$ and acetic acid ( $\geq 99.0 \%)$ were purchased from Daejung Chemicals (Korea) and used as solvents without further purification.

\section{Multi-jet electrospinning}

To obtain uniform PS fibers, 18 wt\% PS solution was prepared with DMF/THF mixture in a weight ratio of 3/1. $18 \mathrm{wt} \%$ PA6 solution was prepared with a formic acid/acetic acid

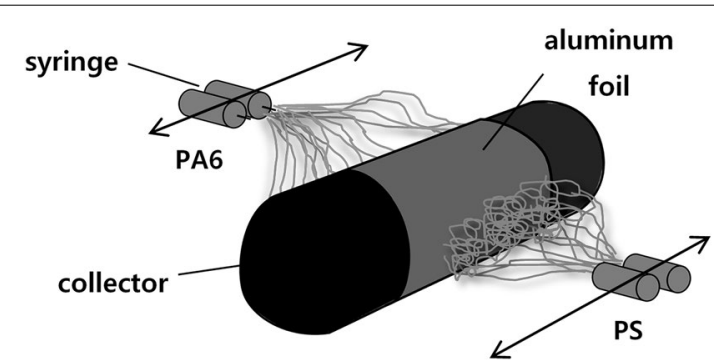

Fig. 1 Schematic on multi-jet electrospinning set-up 
mixture in a weight ratio of 4/1. ES-robot ${ }^{\circledR}$ Electrospinning/spray system (Nano NC, Korea) was used. A multi-jet electrospinning set up is illustrated in Fig. 1. Two syringes with needles (gauge 22G) were placed in the front and back side of grounded stainless drum collector respectively, and polymer solution was ejected toward the collector rotating at a speed of $100 \mathrm{rpm}$. The ejecting syringe was horizontally moved along the track with a speed of $7 \mathrm{~m} / \mathrm{min}$. Electric voltage of $20 \mathrm{kV}$ was applied to the tip, and a collector to tip distance was maintained at $20 \mathrm{~cm}$. Environmental temperature was kept at $25 \pm 5^{\circ} \mathrm{C}$ and humidity was $40 \pm 5 \mathrm{RH} \%$ if not specified. To obtain the varied contents of PS and PA6 in the blend web, the number of syringes containing PS or PA6 solutions were varied as $4 / 0,3 / 1,2 / 1,2 / 2,1 / 2,1 / 3$ and $0 / 4$, and a constant solution feeding rate of $0.2 \mathrm{ml} / \mathrm{h}$ was maintained. All webs were made in a thickness range of 56-64 $\mu \mathrm{m}$. Electrospun webs were collected on an aluminum foil, and dried in vacuum at room temperature for $24 \mathrm{~h}$ to evaporate residual solvents.

\section{Characterization}

\section{Determination of PS/PA6 blend ratio}

The blend web was observed for its PS and PA6 contents by the chemical immersion test (adjusted KS K ISO 1833 method) and confocal microscopy (LSM 700, Carl Zeiss, Germany) analysis after dyeing the respective fibers with different fluorescent dyes.

The contents of PS and PA6 in the blend electrospun web were investigated by immersing the dried blend web into formic acid to remove the PA6 component. The immersed web was thoroughly washed with formic acid and distilled water then dried. The content of PA6 was calculated by the weight loss of the web.

PS was dyed with rhodamin B ( $\geq 95.0 \%$, HPLC grade, Sigma-Aldrich) in $5 \mu \mathrm{g} / \mathrm{ml}$ concentration, and PA6 was dyed with fluorescein isothiocyanate isomer I (FITC, 98.0\%, HPLC grade, Sigma-Aldrich) in $5 \mu \mathrm{g} / \mathrm{ml}$ concentration. The confocal microscopy was taken through the web thickness of $60 \mu \mathrm{m}$ in every $1 \mu \mathrm{m}$ sectional frames. The images were analyzed by Adobe Photoshop CS4 for the number of pixels in red PS fibers and green PA6 fibers to estimate the respective fiber contents in a blend web.

\section{Web morphology}

Fiber morphology was observed by field emission scanning electron microscope (FESEM, JSM-7600F, JEOL, Japan). The fiber diameter of each specimen was measured by image analyzing software, Image J (National Institute of Health, USA). Web configuration with varied environmental humidity during electrospinning process was observed by the photo taken by using Digital Single Lens Reflex (EOS 650D, Canon, Japan) to draw a comparison of the appearance of each web.

\section{Mechanical properties}

Tensile properties were assessed by a universal test machine (UTM, WL 2100, Withlab Co. Ltd., Korea) for a specimen in $40 \times 10 \times 0.06 \mathrm{~mm}^{3}$ in accordance with ASTM D5035 strip method. The gauge length and crosshead speed were $20 \mathrm{~mm} / \mathrm{min}$ and $10 \mathrm{~mm} / \mathrm{min}$, respectively. The average of five measurements was used for analysis. 


\section{Air and water vapor permeability}

Pore size and distribution of the web were measured using capillary pressure tester (CFP-1500 Porometer, PMI, USA) at the maximum pressure of 200 psi and the maximum flow rate $25,000 \mathrm{ml} / \mathrm{min}$. The apparent density of blend webs was measured by Eq. 1:

$$
\text { Apparent density }\left[\mathrm{g} / \mathrm{m}^{3}\right]=\text { mass of web/volume of the web }
$$

Air permeability of the web was characterized using capillary flow porometer (CFP1200, PMI, USA), at the maximum pressure of $200 \mathrm{psi}$ and the maximum flow rate of $25,000 \mathrm{ml} / \mathrm{min}$. In this method, the amount of air $(\mathrm{ml} / \mathrm{s})$ passing through the specimen was measured as the applied air pressure was increased up to the set maximum pressure.

Water vapor transmission rate (WVTR) was measured according to ASTM E 96 desiccant method. A custom-designed cup was filled with calcium chloride, and the web specimen was fixed onto its opening. Then the assembly was kept at $40{ }^{\circ} \mathrm{C}, 90 \% \mathrm{RH}$. After $1 \mathrm{~h}$, the evaporation of water through the specimen was measured by the weight change of the cup.

\section{Surface hydrophilicity}

Surface hydrophilicity of the blend web was measured by static contact angle (SCA) measurement using a contact angle measurement device (Theta Lite, Attention, KSV Instrument, Finland). $4 \mu \mathrm{l}$ droplets of distilled water was placed on five different positions on the sample surface, and the SCA on specimens were measured. SCA changes were recorded for $60 \mathrm{~s}$ of water contact time on the web surface.

\section{Thermal properties}

Thermal conductivity of an electrospun web was measured by KES-F7 System (Thermal Labo II: Kato Tech Co. Ltd, Japan). Thermal resistance was measured using a sweating hotplate device (SGHP-8.2, Measurement Technology Northwest, USA), according to the modified ISO 11,092 sweating guarded-hotplate test method. For measurement of thermal resistance, electrospun web specimen was placed $10 \mathrm{~mm}$ above the hotplate to simulate a micro-environment of still air between human skin and clothes (Kim and Park 2013).

\section{Results and discussion}

\section{Blend Ratio of PS/PA6 Webs}

Content ratio of PS/PA6 of the developed web was measured by the chemical immersion test and the confocal microscopy analysis (Table 1). Overall, the ratio of the number of syringes containing PS to PA6 was similar to blend ratio calculated by immersion test and confocal microscopy analysis. Slight differences were noticed between immersion test and confocal microscopy analysis results. As confocal microscopy was taken for every $1 \mu \mathrm{m}$ of the nonwoven web sections, errors could come from the overlooked areas between the sections. Therefore, the immersion test was considered as more reliable method because the test allows us to measure the whole area of the specimen. Moreover, PA6 fibers were much finer than PS fibers, thus PA6 fibers had larger surface area which might have affected pixel counting. We calculated weight of webs using weight 
Table 1 Characteristics of the electropsun webs

\begin{tabular}{|c|c|c|c|c|c|c|c|}
\hline Code & $\begin{array}{l}\text { Number } \\
\text { ratio of jets } \\
\text { (PS/PA6) }\end{array}$ & $\begin{array}{l}\text { Weight ratio } \\
\text { (confocal } \\
\text { microscopy } \\
\text { analysis) }\end{array}$ & $\begin{array}{l}\text { Blend ratio } \\
\text { (immersion } \\
\text { test) }\end{array}$ & $\begin{array}{l}\text { Calculated } \\
\text { weight }^{\text {a }} \\
\left(\mathrm{g} / \mathrm{m}^{2}\right)\end{array}$ & $\begin{array}{l}\text { Measured } \\
\text { weight } \\
\text { (apparent } \\
\text { density) } \\
\left(\mathrm{g} / \mathrm{m}^{2}\right)\end{array}$ & $\begin{array}{l}\text { Error }^{b} \\
(\%)\end{array}$ & $\begin{array}{l}\text { Thickness } \\
(\mu \mathrm{m})\end{array}$ \\
\hline $\mathrm{S} 4 \mathrm{AO}$ & $4 / 0$ & $100 / 0$ & $100 / 0$ & - & $8.1 \pm 0.4$ & - & $60 \pm 4$ \\
\hline $\mathrm{S} 3 \mathrm{~A} 1$ & $3 / 1$ & $74 / 26$ & $76 / 24$ & 9.2 & $8.7 \pm 0.5$ & 6 & $60 \pm 3$ \\
\hline $\mathrm{S} 2 \mathrm{~A} 1$ & $2 / 1$ & $64 / 36$ & $67 / 33$ & 9.6 & $9.2 \pm 0.5$ & 4 & $60 \pm 2$ \\
\hline $\mathrm{S} 2 \mathrm{~A} 2$ & $2 / 2$ & $48 / 52$ & $51 / 49$ & 10.4 & $9.5 \pm 0.4$ & 9 & $60 \pm 4$ \\
\hline $\mathrm{S} 1 \mathrm{~A} 2$ & $1 / 2$ & $34 / 66$ & $33 / 67$ & 11.2 & $10.0 \pm 0.7$ & 12 & $60 \pm 1$ \\
\hline $\mathrm{S} 1 \mathrm{~A} 3$ & $1 / 3$ & $22 / 78$ & $24 / 76$ & 11.6 & $10.1 \pm 0.5$ & 15 & $60 \pm 2$ \\
\hline SOA4 & $0 / 4$ & $0 / 100$ & $0 / 100$ & - & $12.7 \pm 0.5$ & - & $60 \pm 1$ \\
\hline
\end{tabular}

a Weight was calculated on the assumption that PS weight is 8.1 and PA weight is 12.7 on 6th column

${ }^{\mathrm{b}}$ Error $(\%)=($ calculated weight - measured weight $) /$ measured weight* 100

ratio measured by immersion test (5th column in Table 1) and compared the values to the measured weight (6th column in Table 1). Insignificant error was noticed from our calculated values (7th column in Table 1), but as PA6 content increases error increased as well. This might stem from our calculation based on the measured weight of S4A0 and S0A4 webs. S4A0 weight was underestimated but S0A4 weight was overestimated.

However, confocal microscopy can be applied as a useful quality control technique to examine the fiber uniformity, because it provides the visual image (Fig. 2) of the compositional distribution in blend fiber webs.

\section{Electrospun web morphology}

SEM images of electrospun web with various content ratios of PS to PA6 are shown in Fig. 3. At the same spinning condition, PS fibers were in larger diameter $(0.90 \pm 0.19 \mu \mathrm{m})$ than PA6 fibers $(0.10 \pm 0.03 \mu \mathrm{m})$.

In addition to the diameter difference, more distinctive difference between PS and PA6 fibers was observed from the surface configurations as in Fig. 3a, where PS fiber surface shows corrugations and small pores. The surface configuration is a result of interactions among polymer molecule, solvent, and moisture in the environment. A polymer solution

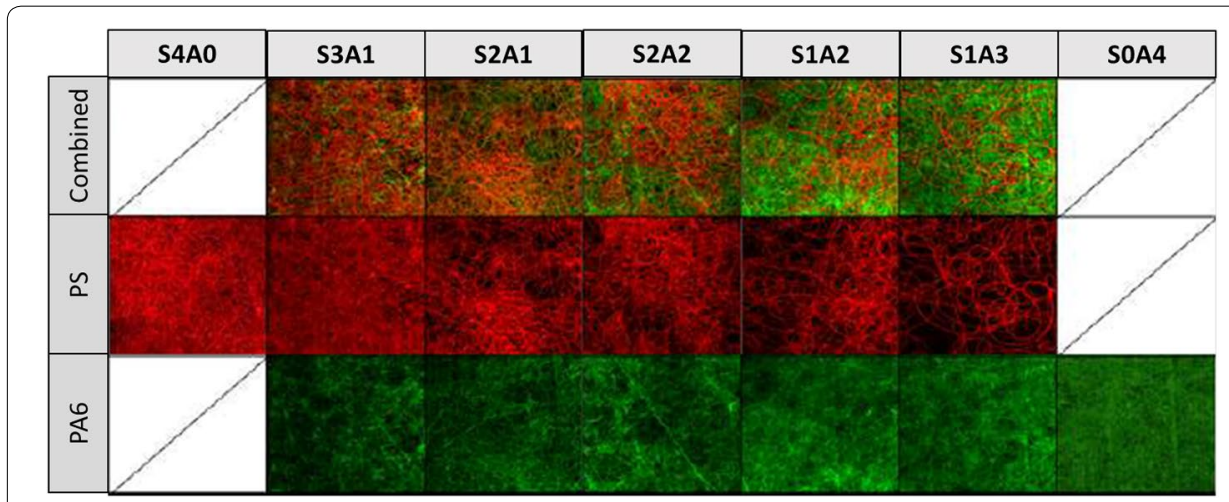

Fig. 2 Confocal microscopy images for the dyed PS/PA6 blend webs: red represents PS fibers and green represents PA6 fibers 

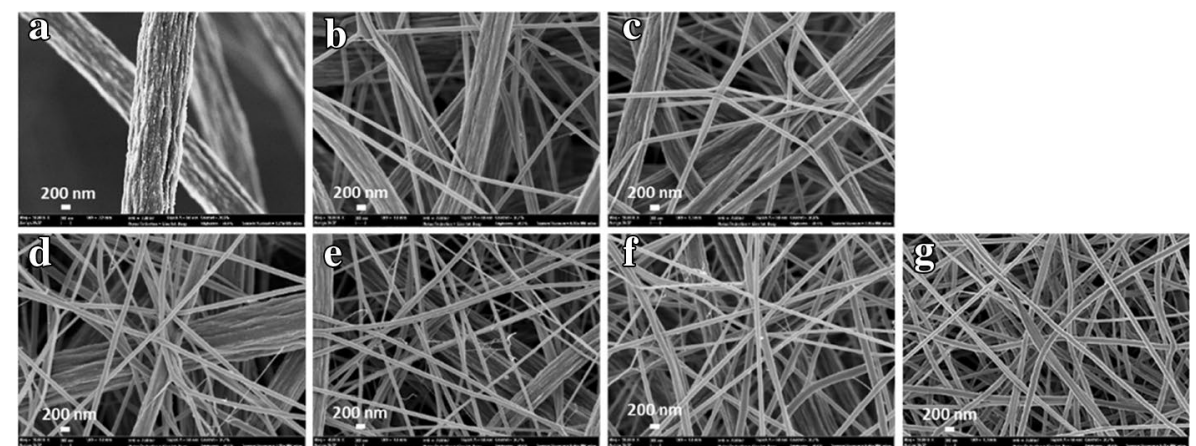

Fig. 3 FE-SEM images of PS/PA6 electrospun webs in various content ratio of PS/PA6: a 4/0, b 3/1, c 2/1, d $2 / 2, \mathbf{e} 1 / 2, \mathbf{f} 1 / 3, \mathbf{g} 0 / 4$

such as PS in a mixture solvent of a highly volatile THF and a less volatile DMF can create porosity and/or corrugations by the vapor-induced phase separation (VIPS) (Casper et al. 2004; Fashandi and Karimi 2012; Lin et al. 2010). When a fluid jet of PS solution is exposed to humid environment, the polymer solution undergoes phase separation into polymer-rich and solvent-rich regions. Then the polymer-rich phase solidifies quickly, whereas the solvent-rich phase delays the solidification. Highly volatile THF in solventrich region contributes to creating small pores at the surface upon its rather faster evaporation, while low volatile DMF contributes to forming corrugations and grooves at the surface by the growth of pores and evolution of channels.

In addition to the effect of binary solvent system, it was also found that 3D configuration of the web could be controlled by the environmental humidity during electrospinning process. Figure 4 presents pure PS and PA6 electrospun webs produced from the varied environmental humidity during electrospinning process. A4 formed a smooth membrane-like surface in all the humidity conditions; however, S4A0 web configuration was highly dependent on humidity condition. With the increased humidity, PS web formed a bulkier and fluffier structure having more air content. This phenomenon can be explained by the repulsive interactions between neighboring PS fibers when they are dissolved in an electrically conductive solvent like DMF and a solvent-rich phase is formed in humid environment (Bonino et al. 2012; Sun et al. 2012). Thus, by choosing the right condition for environmental humidity during electrospinning process and solvent system, 3D web configuration and surface morphology can be controlled for the relevant application. For example, a bulky and porous PS web that is produced in humid and solvent rich condition would make a good material for thermal insulation with large air content in its structure.

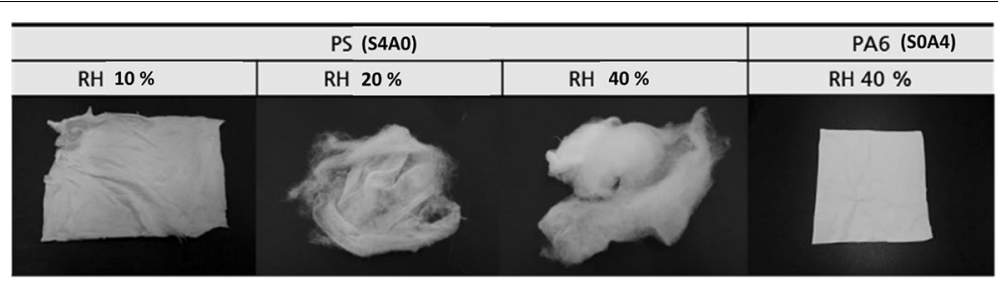

Fig. 4 PS and PA6 webs electrospun in the varied humidity conditions 


\section{Tensile properties}

Tensile property with the varied ratio of PS/PA6 is shown in Fig. 5. PS web had low tensile strength (0.4 MPa) and relatively high strain at break (78\%), while PA6 web showed five times higher strength (2.0 $\mathrm{MPa}, 32 \%$ strain) than PS. The mechanical strength of blend web was enhanced as PA6 content was increased. In the earlier work by Park et al. (2011), lower mechanical strength of PS was attributed to the lack of bonding of PS fibers, fibers being easily slipped when extended. Good mechanical strength of PA6 web may be stem from better bonding by the layers of individual fibers resulting from a slow evaporation of solvent. A relatively high strain at break of S2A2 blend (strain 96\%) can be explained by the lack of bonding in PS fibers in the web, where the fiber slippage and extension occurred up to $96 \%$ strain.

\section{Porosity}

Table 2 shows the total pore volume and \% porosity. S4A0 electrospun web exhibited the largest pore size distribution, pore volume, and porosity due to its relatively bulkier structure (Fig. 3). A4 showed the least pore size distribution, pore volume, and porosity. The total pore volume significantly decreased with the increase of PA6 contents within the blend web, because the smaller size PA6 fibers filled up the large pores formed by PS fibers. Likely, the porosity calculated from the web density was highly influenced by the PA6 content.

\section{Air permeability and water vapor permeability}

Air permeability of the web was measured by the volume of air passing through the web per second with the incremental pressure up to 300 psi (Fig. 6). S4A0 required the lowest pressure to pass the same amount of air, indicating the highest air permeability. Adding PA6 decreased the air permeability. It appears that the porosity is correlated to the air permeability of the web.

Water vapor transmission, however, was not directly associated with the porosity of the web (Fig. 7). Instead, it was influenced both by the porosity and the surface

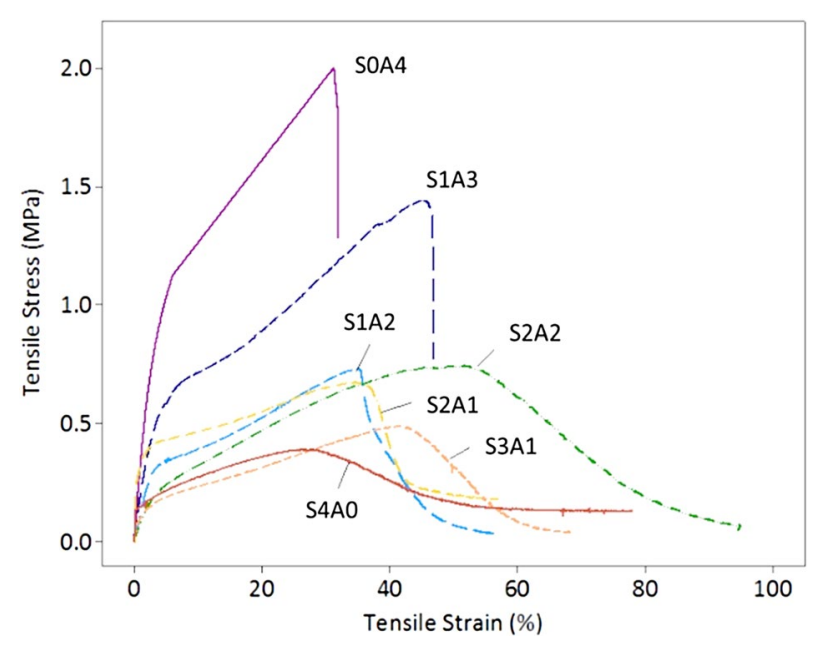

Fig. 5 Stress-strain curve for various contents PS/PA6 webs: a 4/0, b 3/1, c 2/1, d 2/2, e 1/2, f 1/3, g 0/4 
Table 2 Pore size range, total pore volume and porosity of PS/PA6 blend webs

\begin{tabular}{lllll}
\hline Sample & Pore size range $(\boldsymbol{\mu m})$ & Sample density $\left(\mathbf{g} / \mathbf{c m}^{\mathbf{3}}\right)$ & Total pore volume $(\mathbf{m l} / \mathbf{g})$ & $\begin{array}{l}\text { Porosity } \\
(\%)\end{array}$ \\
\hline S4A0 & $0.47-10.20$ & 0.123 & 6.473 & 79.62 \\
S3A1 & $0.11-9.95$ & 0.153 & 4.878 & 74.63 \\
S2A1 & $0.05-9.91$ & 0.170 & 4.214 & 71.63 \\
S2A2 & $0.03-7.23$ & 0.217 & 3.198 & 69.39 \\
S1A2 & $0.01-4.16$ & 0.221 & 3.001 & 66.33 \\
S1A3 & $0.01-5.18$ & 0.257 & 2.398 & 61.62 \\
SOA4 & $0.01-3.75$ & 0.321 & 1.898 & 60.92 \\
\hline
\end{tabular}

${ }^{a}$ Porosity $=$ sample density $\times$ total pore volume $\times 100$

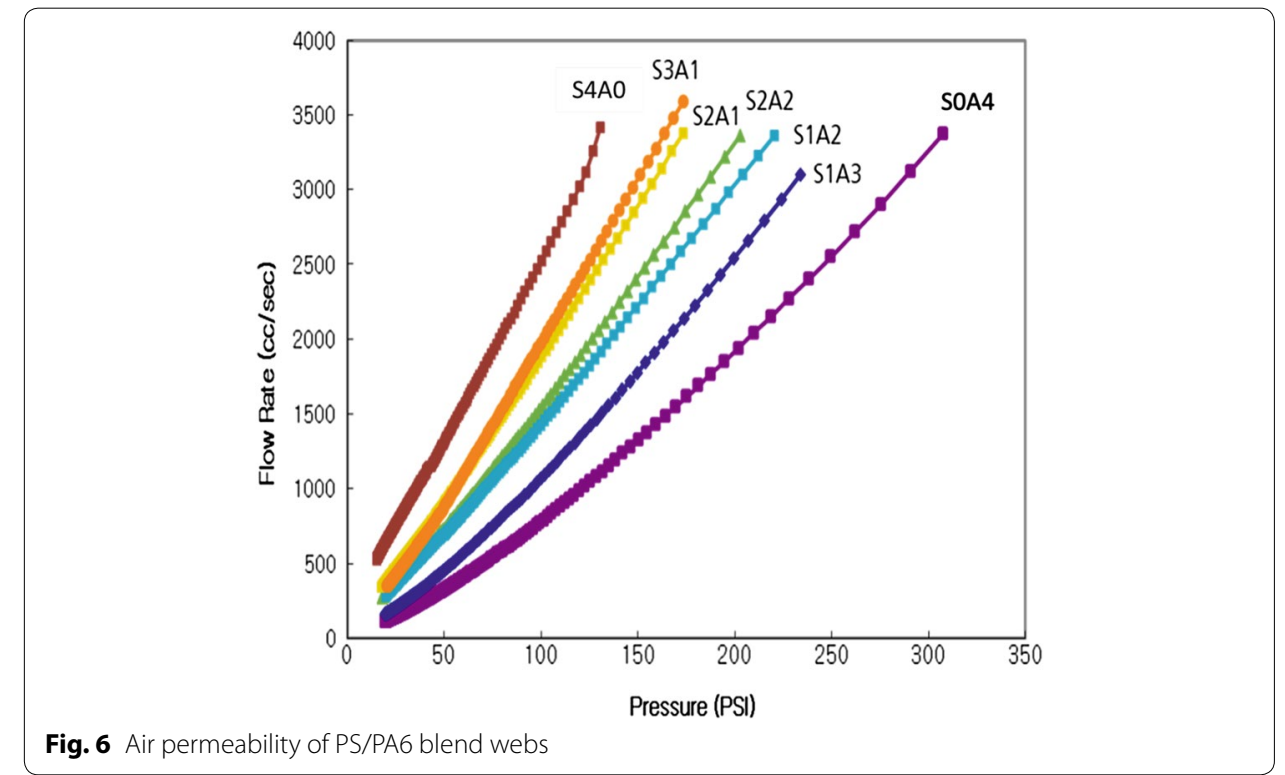

hydrophilicity of webs. Many researchers (Ahn et al. 2011; Gibson 1993; Wehner et al. 1988) have agreed that water vapor travels through air spaces of textiles and experiences absorption and desorption within fibers.

The effect of porosity on water vapor transmission was dominant for S4A0, S3A1, S2A1, S2A2, and S1A2; that is, the increased PA6 content reduced the web porosity, and thus lowered the water vapor transmission. However, when PA6 was further increased in the web content, hydrophilicity by PA6 contributed more to the water vapor transmission, significantly enhancing the water vapor transmission for A4. Thus, when PA6 is blended with PS web, it should be understood that certain comfort properties such as air permeability and water vapor transmission can be compromised in exchange of improved mechanical strength.

\section{Surface hydrophilicity}

Surface hydrophilicity of PS/PA6 blend webs were investigated through static contact angle (SCA) measurements (Fig. 8). S4A0 had high SCA value of $150^{\circ}$ due to the low surface energy and surface roughness coming from PS fiber's wrinkled surface (Fig. 3) 


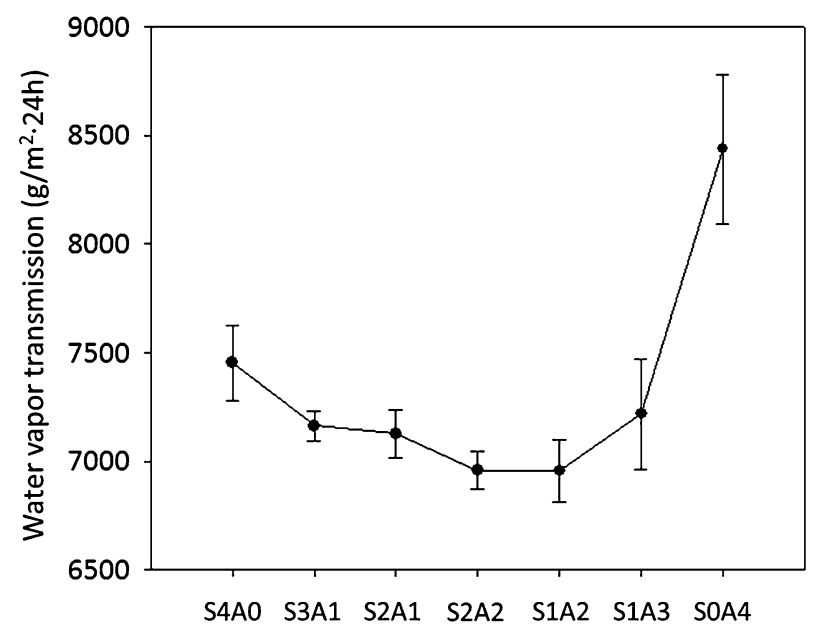

Fig. 7 Water vapor transmission of PS/PA6 blend webs

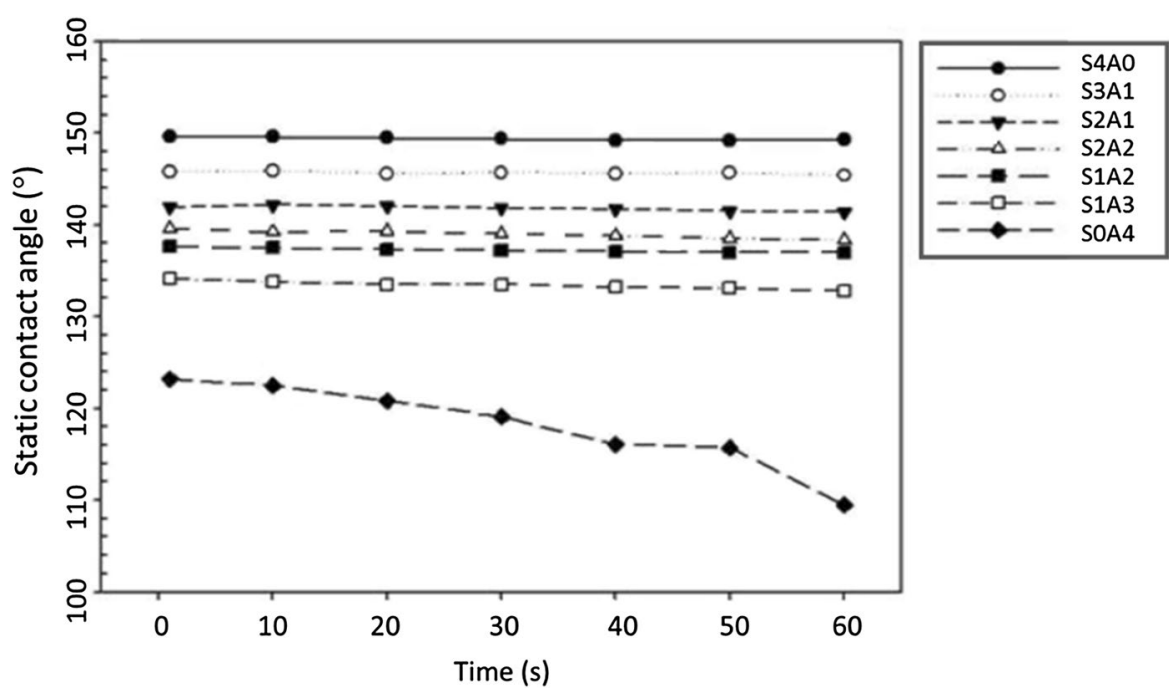

Fig. 8 Static contact angle measurements on PS/PA6 blend webs

(Miyauchi et al. 2006). As the PA6 composition increased, SCA was decreased accordingly. It was because PA6 has higher surface energy $(45.3 \mathrm{mN} / \mathrm{m})$ (Gotoh 2004) than that of PS $(40.7 \mathrm{mN} / \mathrm{m})$ (Harris et al. 2003). Also the phenomenon may be caused by the fact that PA6 fibers were finer and smoother, giving less surface roughness than PS fibers (Fig. 3). All samples except S0A4 maintained consistent SCA for $60 \mathrm{~s}$ of time. Park et al. (2014) suggested that PA6 plain textiles may wet more quickly than PA6 film, because wetting can be facilitated at the textile surface by the wicking through fiber interfaces. Densely packed PA6 fibers of S0A4 sample can possibly promote wicking and spreading, giving a decreasing SCA with $60 \mathrm{~s}$ of time. 


\section{Thermal properties}

As the thermal conductivity of air is as low as $0.025 \mathrm{~W} / \mathrm{m} \mathrm{K}$, thermal conductivity of textile material is largely influenced by air content (Kim and Park 2013). Thermal conductivity for PS film is reported to range in $0.10-0.13 \mathrm{~W} / \mathrm{m} \mathrm{K}$ (Han and Fina $2011 ; \mathrm{Hu}$ et al. 2001) and that of PA6 film to be $0.25 \mathrm{~W} / \mathrm{m} \mathrm{K}$ (Han and Fina 2011). Also, a material with higher density and lower air content is likely to have higher thermal conductivity, deteriorating thermal insulation.

In Fig. 9, as PA6 content increased, thermal conductivity of the web increased, due to PA6's higher thermal conductivity and the lowered porosity (or lower air content). PS fibers not only had larger porosity but also had corrugations on fiber surfaces, resulting in a larger air content for the PS web.

Thermal resistance of the web was linearly reduced with higher PA6 content (Fig. 9). As shown in Fig. 3, finer PA6 fibers appeared to interlace with larger PS fibers, forming a complicated and dense pore structure. The results show that the addition of PA6 can enhance the mechanical strength of the web in the expense of comfort factors in terms of thermal resistance, air permeability, and water vapor transmission.

\section{Conclusion}

To obtain fibrous webs with the high thermal resistance and reasonable mechanical strength, blend webs with PS and PA6 contents were produced by the multi-jet electrospinning process. Confocal microscopy can be used to examine fiber contents and distribution in the web, while immersion test gave more accurate fiber contents of the blend web. Fiber morphology and 3D structure of PS fibrous web were influenced by the environmental humidity during electrospinning process and solvent selection. PS web produced in higher humidity generated more pores and corrugations at the surface. The increased surface roughness and porosity led to the increased hydrophobicity and thermal resistance.

The addition of PA6 to PS enhanced the mechanical strength. However, the added PA6 deteriorated the comfort properties including air permeability, water vapor transmission rate, and thermal resistance. Water vapor transmission of 100\% PA6 web, however, was significantly better than that of blend web due to higher surface hydrophilicity of the web. The lowered thermal resistance by the addition of PA6 is attributed to (1)

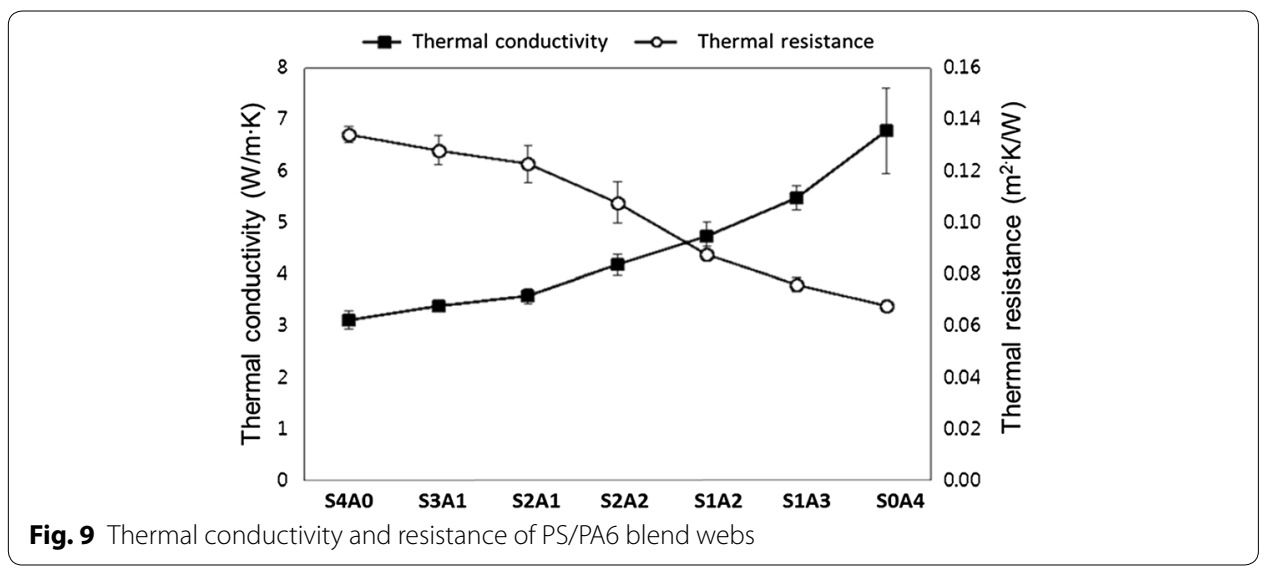


higher thermal conductivity of PA6 material and (2) lowered air content for compact PA6 structure.

The blend ratio of PS/PA6 influenced on blend web structure, morphology, and properties. Future study is needed for the environmental parameters in electrospinning to produce an optimal 3D web structure to achieve the highest thermal resistance. It is recommended to examine the ways to enhance the mechanical strength of the PS web, probably by lowering the rate of solvent evaporation to allow more time for fiber bonding.

\section{Authors' contributions}

All authors were involved in the design of experiments and result discussion. Also, all authors read and approved the final manuscript.

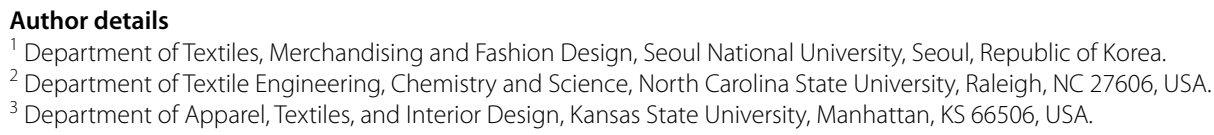

\section{Acknowledgements}

This work was supported by the National Research Foundation of Korea (NRF) grant funded by the Korea government (MSIP: No 2015R1A2A2A03002760) and the BK21 Plus Project funded by the National Research Foundation of Korea.

\section{Competing interests}

On behalf of all authors, the corresponding author states that there is no competing interests.

Received: 16 June 2016 Accepted: 1 November 2016

Published online: 28 April 2017

\section{References}

Ahn, H. W., Park, C. H., \& Chung, S. E. (2011). Waterproof and breathable properties of nanoweb applied clothing. Textile Research Journal, 81, 1438-1447.

Bonino, C. A., Efimenko, K., Jeong, S. I., Krebs, M. D., Alsberg, E., \& Khan, S. A. (2012). Three-dimensional electrospun alginate nanofiber mats via tailored charge repulsions. Small (Weinheim an der Bergstrasse, Germany), 8, 1928-1936.

Carrizales, C., Pelfrey, S., Rincon, R., Eubanks, T. M., Kuang, A., McClure, M. J., et al. (2008). Thermal and mechanical properties of electrospun PMMA, PVC, Nylon 6, and Nylon 6,6. Polymers for Advanced Technology, 19, 124-130.

Casper, C. L., Stephens, J. S., Tassi, N. G., Chase, D. B., \& Rabolt, J. F. (2004). Controlling surface morphology of electrospun polystyrene fibers: Effect of humidity and molecular weight in the electrospinning process. Macromolecules, 37, 573-578.

Cengiz, F., Dao, T. A., \& Jirsak, O. (2010). Influence of solution properties on the roller electrospinning of poly(vinyl alcohol). Polymer Engineering \& Science, 50, 936-943

Ding, B., Kimura, E., Sato, T., Fujita, S., \& Shiratori, S. (2004). Fabrication of blend biodegradable nanofibrous nonwoven mats via multi-jet electrospinning. Polymer, 45, 1895-1902.

Fashandi, H., \& Karimi, M. (2012). Pore formation in polystyrene fiber by superimposing temperature and relative humidity of electrospinning atmosphere. Polymer, 53, 5832-5849.

Gibson, P. (1993). Influencing steady-state heat and water vapor transfer measurements for clothing materials hot plate and upright cup methods of. Textile Research Journal, 63, 749-764.

Gotoh, K. (2004). Wettability and surface free energies of polymeric materials exposed to excimer ultraviolet light and particle deposition onto their surfaces in water. In K. Mittal (Ed.), Polymer surface modification: relevance to adhesion (pp. 125-139). Utrecht: VSP.

Greiner, A., \& Wendorff, J. H. (2007). Electrospinning: A fascinating method for the preparation of ultrathin fibers. Angewante Chemie-International Edition, 46, 5670-5703.

Han, Z., \& Fina, A. (2011). Thermal conductivity of carbon nanotubes and their polymer nanocomposites: A review. Progress in Polymer Science, 36, 914-944.

Harris, M., Appel, G., \& Ade, H. (2003). Surface morphology of annealed polystyrene and poly(methyl methacrylate) thin film blends and bilayers. Macromolecules, 36, 3307-3314.

Hu, C., Kiene, M., \& Ho, P. S. (2001). Thermal conductivity and interfacial thermal resistance of polymeric low k films. Applied Physical Letter, 79, 4121-4123.

Kim, K. S., \& Park, C. H. (2013). Thermal comfort and waterproof-breathable performance of aluminum-coated polyurethane nanowebs. Textile Research Journal, 83, 1808-1820.

Li, D., \& Xia, Y. (2004). Electrospinning of nanofibers: Reinventing the wheel? Advanced Materials, 16, 1151-1170.

Lin, J., Ding, B., Jianyong, Y., \& Hsieh, Y. (2010). Direct fabrication of highly nanoporous polystyrene fibers via electrospinning. ACS Applied Materials \& Interfaces, 2, 521-528.

Marsano, E., Francis, L., \& Giunco, F. (2010). Polyamide 6 nanofibrous nonwovens via electrospinning. Journal of Applied Polymer Science, $117,1754-1765$ 
Miyauchi, Y., Ding, B., \& Shiratori, S. (2006). Fabrication of a silver-ragwort-leaf-like super-hydrophobic micro/nanoporous fibrous mat surface by electrospinning. Nanotechnology, 17, 5151-5156.

Pai, C. L., Boyce, M. C., \& Rutledge, G. C. (2009). Morphology of porous and wrinkled fibers of polystyrene electrospun from dimethylformamide. Macromolecules, 42, 2102-2114.

Park, C. H., Kim, C. H., Pant, H. R., Tijing, L. D., Yu, M. H., Kim, Y., et al. (2013). An angled robotic dual-nozzle electrospinning set-up for preparing PU/PA6 nanofiber composites. Textile Research Journal, 83, 311-320.

Park, D.-K., Park, S.-J., Baek, W.-I., Kanjwal, M. A., \& Kim, H.-Y. (2011). Point-bonded electrospun polystyrene fibrous mats fabricated via the addition of poly(butylacrylate) adhesive. Polymer Engineering \& Science, 51, 894-901.

Park, Y., Park, C. H., \& Kim, J. (2014). A quantitative analysis on the surface roughness and the level of hydrophobicity for superhydrophobic ZnO nanorods grown textiles. Textile Research Journal, 84, 1776-1788.

Pham, Q. P., Sharma, U., \& Mikos, A. G. (2006). Electrospinning of polymeric nanofibers for tissue engineering applications: A review. Tissue Engineering, 12, 1197-1211.

Reneker, D. H., \& Chun, I. (1996). Nanometre diameter fibres of polymer, produced by electrospinning. Nanotechnology, 7, 216-223.

Sun, B., Long, Y.-Z., Yu, F., Li, M.-M., Zhang, H.-D., Li, W.-J., et al. (2012). Self-assembly of a three-dimensional fibrous polymer sponge by electrospinning. Nanoscale, 4, 2134-2137.

Teo, W. E., \& Ramakrishna, S. (2006). A review on electrospinning design and nanofibre assemblies. Nanotechnology, 17, 89-106.

Wehner, J. A., Miller, B., \& Rebenfeld, L. (1988). Dynamics of water vapor transmission through fabric barriers. Textile Research Journal, 58, 581-592.

Yener, F., \& Jirsak, O. (2012). Comparison between the needle and roller electrospinning of polyvinylbutyral. Journal of Nanomaterials, 2012,1-6.

\section{Submit your manuscript to a SpringerOpen ${ }^{\circ}$ journal and benefit from:}

- Convenient online submission

- Rigorous peer review

- Immediate publication on acceptance

- Open access: articles freely available online

- High visibility within the field

- Retaining the copyright to your article

Submit your next manuscript at $\boldsymbol{\nabla}$ springeropen.com 